\title{
Usefulness of virtual bronchoscopy in evaluation of suspected foreign body in tracheobronchial tree
}

\author{
Mohit Srivastava*, Sushant Tyagi
}

Department of ENT, Saraswathi Institute of Medical Sciences, Anwarpur, Hapur, Uttar Pradesh, India

Received: 10 October 2015

Accepted: 05 December 2015

\author{
*Correspondence: \\ Dr. Mohit Srivastava, \\ E-mail: dr.mohit141180@gmail.com
}

Copyright: () the author(s), publisher and licensee Medip Academy. This is an open-access article distributed under the terms of the Creative Commons Attribution Non-Commercial License, which permits unrestricted non-commercial use, distribution, and reproduction in any medium, provided the original work is properly cited.

\begin{abstract}
Background: Airway foreign bodies remain a diagnostic challenge to health care professionals. They can become life threatening emergencies that require immediate intervention or can go unnoticed for weeks and even months. Every effort should be made to avoid a delay in diagnosis because this may lead to a notable increase in complication rates. The objective of this study is to investigate the usefulness of virtual bronchoscopy in evaluation of suspected foreign body aspiration in tracheobronchial tree.

Methods: This retrospective \& prospective study of 100 patients is conducted in the department of otorhinolaryngology \& Head \& Neck Surgery, Saraswathi Institute of Medical sciences, Hapur, Uttar Pradesh, India; from August 2011 to August 2015. Cases referred from department of paediatrics, with history of sudden breathlessness, sudden onset of cough with or without cyanosis \& with or without pyrexia.

Results: In our studies highest incidence of foreign bodies i.e. $61 \%$ were seen in the children between the age of 1-5 yrs $73 \%$ cases were male children while $27 \%$ were female children. Incidence of FB was quite higher in low socio economic status group (63\%) as compared to middle class (34\%) In our studies maximum no of cases i.e. $31 \%$ were betel nut followed by custard apple $22 \%$. Others include gram seed $(8 \%)$, tamarind seed (6\%), coconut (5\%) and ground nut $(10 \%)$. In our studies, majority of FB in air passage were in right main bronchus $57 \%$ followed by upper air passage $(22 \%) \& 21 \%$ in left main bronchus.

Conclusions: FB aspiration is an anaesthetic emergency and senior help should be sought early. Techniques should be tailored to the clinical context but spontaneous respiration should be maintained wherever possible. VB is proving to be a very helpful investigation modality in patients of a compromised airway. VB works well in planning the further management protocol not only in conjunction with other modalities but also on its own It is accurate but its accuracy is not $100 \%$ because of false positive \& false negative results. VB will never replace actual bronchoscopy (gold standard) but it can assist \& complement it.
\end{abstract}

Keywords: Virtual bronchoscopy, Foreign body aspiration, Tracheobronchial tree

\section{INTRODUCTION}

Airway foreign bodies remain a diagnostic challenge to health care professionals. They can become life threatening emergencies that require immediate intervention or can go unnoticed for weeks and even months. Every effort should be made to avoid a delay in diagnosis because this may lead to a notable increase in complication rates. A sudden onset of respiratory symptoms must alert the clinician to the presence of a foreign body. ${ }^{1}$ Airway foreign body present with coughing, choking, acute dyspnoea and sudden onset of wheezing. Prevention is best but early recognition remains a critical factor in the treatment of foreign body inhalation in children. ${ }^{2}$ Diagnosis of such airway foreign body (FB) rests on a relatively new imaging modality Virtual bronchoscopy. Virtual bronchoscopy (VB) is software based, three dimensional visualization formats created from noninvasive medical imaging methods such 
as CT \& magnetic resonance imaging, with the goal of creating views similar to minimally invasive bronchoscopy procedure. This technique offers a detailed view of the airways, with reduced risk of infection or perforation and facilitates preoperative planning for airway interventions that would otherwise not be possible. ${ }^{3}$ In presence of a positive clinical diagnosis \& inconclusive chest radiography, CT virtual bronchoscopy must be considered in all cases of tracheobronchial FB aspiration, in order to avoid needless rigid bronchoscopy. Virtual bronchoscopy simulates an endoscopist's view of the internal surface of the airway. It gives excellent results regarding location, severity and shape of airway narrowing.

\section{METHODS}

This retrospective \& Prospective Study of 100 patients is conducted in the Department of otorhinolaryngology \& Head \& Neck Surgery, Saraswathi institute of medical sciences, Hapur (U.P) from August 2011 to August 2015.

\section{Selection and description of participants}

Patient attending outpatient department of otorhinolaryngology deptt \& casualty services of Saraswathi institute of medical sciences, Hapur, U.P. Patient referred from peripheral \& other district hospitals of UP .Cases referred from department of pediatrics, with history of sudden breathlessness, sudden onset of cough with or without cyanosis \& with or without pyrexia.

\section{Technical information}

A detailed history regarding presenting complaints, history of present illness, past history \& family history was taken. Systemic disorders like T.B, Bronchial asthma, congenital heart disease were ruled out. Examination of nose, ear and throat along with general physical and systemic examination were carried out. Auscultation of the chest for air entry and adventitious sounds were carried out, oxygen saturation measured. Routine hematological tests i.e. Hemoglobin, TWBC, DC, ESR, BT, CT, blood urea and serum creatinine, blood sugar were done. Patients undergone a detailed radiological investigation; X-ray chest (PA) view, X-ray ST neck lateral view followed by CT Virtual bronchoscopy to asses site, shape, size and nature of FB. The cross sectional images were transferred to an attached work station and analysed using Dicom compatible software. Navigation was possible upto the level of the segmental bronchi. All axial images were evaluated for the presence or absence of foreign bodies, using standard lung and soft tissue settings (window 1400 and level-450, and window 300 and level 50, respectively). Any additional parenchymal and mediastinal abnormalities were noted. Interactive navigation through tracheobronchial tree was performed using the computer and mouse. The generation of virtual bronchoscopic images was performed in three stages. The virtual images for each patient were saved as digital files. The axial images and virtual bronchoscopic images were evaluated together, and reported by an experienced radiologist. All patient underwent endoscopic evaluation as early as possible not later than $24 \mathrm{hrs}$ following CT virtual bronchoscopy.

\section{Statistics}

The rigid broncoscopy results were used as a reference for comparison with the VB results. Qualitative results regarding the description of tracheobronchial abnormalities with VB were defined as true-positive, true-negative, false-positive and false-negative findings. The data was evaluated using SPSS 16.0 and p-value of $<0.05$ was considered statistically significant.

\section{RESULTS}

In the present series the maximum number i.e. $61 / 100$ cases belong to age group 1-5 years. $25 \%$ cases were less than $1 \mathrm{yr}$ of age \& $14 \%$ cases were more than 5 yrs of age. In the present series we observed that $73 \%$ cases were male children while $27 \%$ were female children. The sex incidence shows that male predominated with the ratio of 4:1. Most of the patients i.e. $63 \%$ of cases belong to the lower socioeconomic status. $34 \%$ belong to middle class .Only $3 \%$ cases belong to upper class. In the present series, maximum no of cases i.e. $31 \%$ are betel nut followed by custard apple $22 \%$.Ground nut was seen in $10 \%$ cases. Tamarind seed was seen in $6 \%$ cases .Non vegetative FB was seen in only $8 \%$ cases. Majority of FB in air passage were in right main bronchus $57 \%$ followed by upper air passage $(22 \%) \&$ left main bronchus $(21 \%)$. Most cases of FB inhalation i.e. $30 \%$ were in Dewy season followed by rainy season (17 \%).In Autumn incidence was $14 \%$ while in summer, winter and spring it was $13 \%$. Almost all patients $(100 \%)$ presented with varying degree of respiratory distress with cough as the 2nd most common symptom (69\% cases).29\% pts had noisy breathing while only $9 \%$ had fever. CXR was normal in $40 \%$ cases while obstructive emphysema was most common pathological finding $(44 \%)$ in patients with FB aspiration. Other findings include consolidation in 10 $\%$ cases and collapse in $6 \%$ cases.

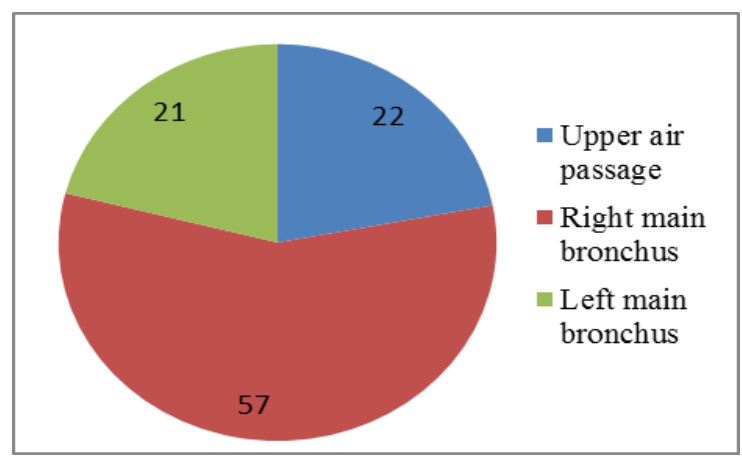

Figure 1: Diagram showing site of FB in air passage. 


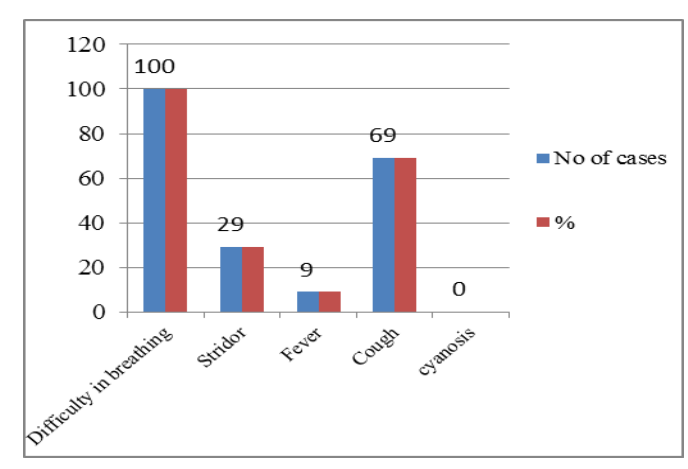

Figure 2: Diagram showing symptom distribution of patients.

\section{DISCUSSION}

FB aspiration in tracheobronchial tree is one of the common problems met with day to day otorhinolaryngological practice and the victims are mainly children. In our country a substantial number of babies must be succumbing to this problem before appropriate health care can be arranged. It is important for the first treating physician to suspect FB if there is sudden onset of respiratory symptoms or there is history of choking. Ezer SS et al found a positive correlation between presence of wheezing and FB positive patients \& found sensitivity of triad (cough, wheezing \& diminished breath sound) in diagnosis of airway FB to be $88 \% .^{4}$ In our studies highest incidence of foreign bodies i.e. $61 \%$ were seen in the children between the age of 1-5 yrs and next most common age group was 0-11 mnth (25\%). Incidence of FB is less among elder children \& adults. Our findings are in similarity to those of François $\mathrm{M}$ et al who also in their studies found $71 \%$ children less than 3 yrs of age. 5

The sex incidence showed male predominance WITH $\mathrm{M}: \mathrm{F} ; 4: 1$. This can be explained as male children being more active and notorious. In study of Hollinger L.D, male to female ratio was $2: 1 .^{6}$ Arvind Seghal et al in their studies concluded M:F ratio 2.1:1. ${ }^{7}$ In our studies, Incidence of FB was quite higher in low socio economic status group (63\%). This directly reflected the surrounding \& personal care of the young children by parents. Social education \& personal habit also determines the incidence rate of FB in airways. In our studies, FB inhalation in airways most commonly seen in children belonging to rural areas (70\%) as compared to urban areas $(30 \%)$ as there is lack of awareness and care for children amongst rural population. Ramírez-Figueroa $\mathrm{JL}$ et al stated that $64.4 \% \mathrm{FB}$ were organic in nature, mainly peanuts, seeds, and beans, while $(35.6 \%)$ were inorganic. ${ }^{8}$

In our studies maximum no of cases i.e. $31 \%$ were betel nut followed by custard apple $22 \%$. Other includes gram seed $(8 \%)$, tamarind seed $(6 \%)$, coconut $(5 \%)$ and ground nut $(10 \%)$. Food items, especially peanuts, are the most common items aspirated in infants and toddlers, whereas older children are more likely to aspirate non-food items such as pen caps, pins, and paper clips. ${ }^{9}$ In our studies, majority of FB in air passage were in right main bronchus $57 \%$ followed by upper air passage $(22 \%) \& 21 \%$ in left main bronchus.Our findings are in accordance with Cataneo AJ, Reibscheid SM who in their studies of 74 patients suffering FBA, reported that the foreign body was lodged in the right bronchus in $50 \%$ of the patients, in the left bronchus in $35 \%$ and in the trachea in $15 \% .^{10}$ Jackson \& Jackson said that there are four types of obstruction namely by-pass valve obstruction like a partially closed valve, check -valve obstruction in which air passes in but not out (emphysema), ball-valve obstruction in which air emerges but cannot enter, shut valve obstruction in which the air cannot pass either in or out, the retained air becoming absorbed (atelectasis). ${ }^{11}$ In our studies, most cases of FB, 30\% came to hospital in Dewy season (Oct-Nov) which is also a festive season in India, followed by rainy (Jun-July) in $17 \%$ cases. Paola Zaupa et al in their studies noted a marked increase in number was evident during the festive season in December. $^{12}$ In our study, breathlessness was the most common symptom $(100 \%)$, it varied from mild to severe degree in almost all cases. Cough was second most. Hollinger (1962) stated that varied symptomatology of tracheobronchial FB depends on its character, size, shape, site of FB age of host \& relative area of lung involvement are other factors giving rise to symptoms.

Our findings are consistent with those of Amir Kugelman et al who also in their studies stated that choking and acute cough are the most common presenting symptoms of FBA. ${ }^{13}$

According to Burton EM et al cough and wheezing were the most common symptoms. ${ }^{14}$

The sensitivity of a chest radiograph in diagnosis of FB aspiration is $82 \%$ and specificity $44 \% .{ }^{15} \mathrm{Chest}$ radiography is the preferred initial investigation in cases of tracheobronchial FB aspiration. Unfortunately, almost $90 \%$ FBs are radioluscent and $30 \%$ of the chest radiographs inconclusive. So a negative chest radiograph does not rule out FB in airway. Wolach B et al observed that clinical signs and radiological studies, in most children, were pathognomonic, but sometimes not conclusive. ${ }^{16}$ Chest X-rays were normal in $18 \%$ cases. In our study Chest X-ray was normal in $40 \%$ cases while obstructive emphysema (44\%) was most common pathological finding in patients with FB aspiration. However because diagnosis was not confirmatory by radiograph further evaluation was done by virtual bronchoscopy. Total number of virtual bronchoscopic reported cases of FB is $100 \&$ when compared with gold standard bronchoscopic finding, in $100 \%$ cases it came as true. In our series all the tracheobronchial FBs were successfully removed by rigid bronchoscopy (Karl Storz, Tuttlingen, Germany with caliber $2.5,3.5,4,4.5 \& 6$ according to the age $\&$ built of patient) after following adequate pre-operative measures. Check bronchoscopy 
after successful removal of FB was always done to clear secretions, residual granulations, to rule out the presence of multiple FB \& residual FB. Subglottic oedema and laryngeal spasm are the two most common complications of bronchoscopy which occur mostly because of repeated instrumentation. The possibility of complications is increased when removing a retained FB. Removal may be hampered by poor visualization associated with swelling, granulation or bleeding.

The long duration of the procedure, presence of dense granulation tissue, and type of foreign body are important predictors of complications. ${ }^{17}$

\section{CONCLUSION}

FB aspiration is an anaesthetic emergency and senior help should be sought early. Techniques should be tailored to the clinical context but spontaneous respiration should be maintained wherever possible. Understand the limitations of imaging techniques such as chest radiographs: plastic is radiolucent. Diagnosis depends on high level of suspicion in a child with sudden onset respiratory distress. Children witnessed to choke while having small particles in their mouths and noted subsequently to have raspy respiration, wheezing, or coughing should undergo prompt bronchoscopy regardless of radiographic findings. $\mathrm{VB}$ is proving to be a very helpful investigation modality in patients of a compromised airway. VB works well in planning the further management protocol not only in conjunction with other modalities but also on its own. It is accurate but its accuracy is not $100 \%$ because of false positive $\&$ false negative results. VB will never replace actual bronchoscopy (gold standard) but it can assist \& complement it. In conclusion the results of bronchoscopy are very satisfying when the child recovers from airway obstruction. This can be achieved by early diagnosis, supervised transportation to a good centre and rigid bronchoscopy by an expert team with back up ICU facility.

\section{Funding: No funding sources}

Conflict of interest: None declared

Ethical approval: The study was approved by the Institutional Ethics Committee

\section{REFERENCES}

1. Mu L, He P, Sun D. The causes and complications of late diagnosis of foreign body aspiration in children. Report of 210 cases. Arch Otolaryngol Head Neck Surg. 1991;117(8):876-9.

2. Passàli D, Lauriello M, Bellussi L, Passali GC, Passali FM, Gregori D. Foreign body inhalation in children: an update. Acta Otorhinolarygologica Italica. 2010;30(1):27-32.

3. Bauer TL Steiner KV. Virtual bronchoscopy; clinical applications \& limitations. Surg oncol clin N America. 2007;16:323-28.
4. Ezer SS, Oguzkurt P, Ince E, Temiz A, Çalskan E, Hicsonmez A. Foreign body aspiration in children: analysis of diagnostic criteria and accurate time for bronchoscopy. Pediatric emergency care. 2011;27(8):723-6.

5. Francois M, Maisani D, Prévost C, Roulleau P. Endoscopy for exploration for foreign bodies of the lower respiratory tract of the child. Apropos of 668 cases. Ann Otolaryngol Chir Cervicofac. 1985; 102(6):433-41.

6. Holinger LD. Foreign bodies of airway \& oesophagus. In: Cummings otolaryngology head \& neck surgery. 5th ed. Philadelphia: Elsevier publishication; 2010:2936-2945.

7. Seghal A, Singh V. FB aspiration, Indian Pediatrics -editorial. 2002;39:1006-10.

8. Ramirez-Figueroa JL, Gochicoa-Rangel LG, Ramirez-San Juan DH, Vargas MH. Foreign body removal by flexible fiberoptic bronchoscopy in infants and children. Pediatr Pulmonol. 2005;40:392.

9. Fitzpatrick PC, Guarisco JL. Pediatric airway foreign bodies. J La State Med Soc. 1998;150:138.

10. Cataneo AJ, Reibscheid SM, Ruiz Júnior RL, Ferrari GF. Foreign body in the tracheobronchial tree. Clin Pediatr (Phila). 1997;36(12):701-6.

11. Jackson C, Jackson CL. Foreign bodies in air \& food passages. In: Bronchoesophagology. Philadelphia \& London: W.B. Saunders \& Co; 1945:738-748.

12. Zaupa P, Saxena AK, Barounig A, Micheal E. Höllwarth. Management strategies in foreign-body aspiration. Indian Journal of Pediatrics. 2009;76(2):57-161.

13. Kugelman A, Shaoul R, Goldsher M, Srugo I. Persistent cough and failure to thrive: a presentation of foreign body aspiration in a child with asthma. Pediatrics. 2006;117:e1057.

14. Burton EM, Brick WG, Hall JD, Riggs W Jr, Houston CS. Tracheobronchial foreign body aspiration in children. South Med J. 1996;89:195-8.

15. Hoeve LJ, Rombout J, Pot DJ. Foreign body aspiration in children. The diagnostic value of signs, symptoms and pre-operative examination. Clin Otolaryngol. 1993;18(1):55-7.

16. Wolach B, Raz A, Weinberg J. Aspirated FB in the respiratory tract of children:eleven years of experience with 127 patients. Int $\mathbf{J}$ Pediatr Otorhinolaryngol. 1994:30(1):1-10.

17. Ciftci AO, Bingol-Kologlu M, Senocak ME, Tanyel FC, Buyukpamukcu N. Bronchoscopy for evaluation of foreign body aspiration in children. $\mathrm{J}$ Pediatr Surg 2003;38(8):1170-6.

Cite this article as: Srivastava $M$, Tyagi $S$.

Usefulness of virtual bronchoscopy in evaluation of suspected foreign body in tracheobronchial tree. Int J Otorhinolaryngol Head Neck Surg 2016;2:18-21. 